\title{
Studying attention levels of the university students from various sport branches
}

\author{
Baybars Recep Eynur ${ }^{1 a}$, Aytul Eynur ${ }^{1}$, and Mustafa Said Erzeybek ${ }^{1}$ \\ ${ }^{1}$ Dumlupinar University, Department of Physical Education and Sport, 43020 Kütahya, Turkey
}

\begin{abstract}
The objective of this study is to examine the attention skills of the university student athletes from various sport branches. A total of 174 university students have been participated into the study of which $46.6 \%$ were female and $53.4 \%$ were male. The neurofeedback method has been used in the study. With regard to the research statistics, the independent variable t-test and ANOVA have been used; and in order to evaluate the diversity of the subgroups, Bonferroni and Tamhane $(\alpha=0.05)$ have been used. The study has revealed that female athletes are significantly more succeful in terms of attention consistency, staying focused against time, controlling attention, hand-eye-brain coordination, and concentration compared to male athletes $(p<0.05)$. It has been seen that the number of years spent doing sports (years of sports) is not an active variable with regard to the attention skills $(\mathrm{p}>0.05)$. It has also been seen that on the basis of the branches, the spatial memory skills of the wrestlers are significantly higher than the soccer players $(\mathrm{p}<0.05)$; that the attention consistency, visual follow-up and staying focused despite the distractors skills of the national athletes are significantly higher than others $(p<0.05)$. The reseach has revealed that attention is instantaneous and definitely an important factor for the sportive success; and besides its unique efficiency for experience and success, also similarly with the sportive success, it exists with "You can succeed only if you do it" understanding.
\end{abstract} Keywords: Attention skills, university students, sport branches.

\section{Introduction and objective}

Many studies have already revealed that a lot of factors affect the success in performance sports and the trainings should cover a wide range of purposes as is widely accepted around the world [1]. The current situation shows that what is underlying the sportive competition and what is perceived as a set of psycho-motor movements may be something more than psycho-motor acitivities of that sport; something that also comprises a mental process [2]. The studies conducted have revealed that any skill can be manifested only and only if all of the appropriate mental processes are passed through $[3,4]$.

\footnotetext{
${ }^{a}$ Corresponding author: baybars.eynur@dpu.edu.tr
} 
This fact has caused the thought "no sportive competition can be succesful without reaching the required mental concentration" to be spread widely. Accordingly, in order to reach the appropriate performance level, one should take part in competition with an appropriate mental state. This study has been regarded significant since it targets to determine the attention levels shown by the athletes from the different branches in different situations as defined with certain measurements upon reaching the required brain frequencies levels; as well as to reveal the sport lives of the athletes and their present efficiencies/inadequacies.

The attention deficit that we encounter more and more nowadays is a disorder that is not much cared by individuals, however it reduces the quality of life significantly, if not treated $[5,6]$. This situation is defined as bad mood in the life span [5]. Since the recent studies have reported that the elite athletes show an increasing tendency toward the attention deficit, a more careful and analytical examination is necessary [7]. It is seen that the studies regarding the attention deficit have been conducted from 1980's to date [8].

Examining the literature shows that most of the studies regarding the attention deficit are based on the individuals with the attention deficit disorder, but certain studies involving the sports have also been encountered [9-12]. These studies have reported that the sports can be an auxilliary element in order to eliminate the attention deficit. However, there was no written descriptive study that concerns the determination of the attention levels of the athletes or the attention level required for the appropriate performance level in the literature. This study targets to analyse the sportive attention in terms of the branch, gender, being national or non-national athlete variables and the individual or team characteristic of the concerned sport.

It is considered that the present study would enable the performance awareness of the athletes as well as help to increase their mental skill levels.

\subsection{Attention}

More than a century ago, William JAMES wrote "everybody knows what is attention" and expressed this as "Embracement of any instantaneously emerged object or thought by the mind clearly and explicitly [13]. The fundemental elements of attention are focusing, concentration and consciousness. Attention means to give up certain things in order to deal efficiently with others."[14].

The first scientific reference about attention was from Descartes as seen by tracing back his etymology to Rome. Descartes has associated attention with the reactions of the pineal body active in the animal soul [15]. Again, the same study claims that attention is a prerequisite for the perception [15].

In another statement, attention is defined in more general terms as the "concentration of the mental efforts on sensual or mental events" [13]. Within this process, attention is also included together with several other mental activities and its importance is highlighted [16]. In addition, the influence of attention in terms of directing and sustaining the learning efforts is emphasized [17-19].

The psychological studies regarding attention describe it with at least six definitions and emphasize the effectiveness of three dimensions in the description process. These are awareness, ability to select information and attention sense that is the product of limited information processing capacity [20].

At this point, attention is defined as a mental process carried out by focusing. Also, the maintainability of attention is defined as the ability to draw away oneself from the environmental events [21].

The general definition of attention that was read as how we perceive the truth underlying a certain act, has been changed when focused attention allowed the individual to 
accept mentally the influences of the observed subject by the individual. Attention that is segmented properly, reunite at certain point that represent the truth as a whole without focusing on any part specifically and at this point the individual selects his/her orientation using all of the senses. Studying attention is closely related with what happens now, but equally away from what could be happened. This situation can be maintained mentally upon determining new ways of thinking and what may come out. The concept of attention also concerns the success capacity with the experience of the unknown, as much as that of the known. Those listed under the term and expression of attention refer to a significant depth and richness as well as both active and passive words. An improved attention capacity allows us to know what happens now, rather than what has been done. Bion's approach goes a little beyond this idea; he reports that the quality of the complete attention enables us to know not only what happens now or what we do, but also what others do. The idea of attention that defines the ability of our minds to get opened to the space, has been used as to focus on a certain point despite all other things around. Bion claims that what underlies the poor quality of attention are observation errors and reasonably, observations' focus on the inconsistency. Attention means maintaining our thoughts with a strong thinking support; the thoughts except those we have abandoned, vain and not consistent with our purposes. Accordingly, attention is a deep awareness, beyond focusing. Consequently, attention is an effect that explore the exact solution of the problems through development, learning, openness for change and continous renewal [22].

The only central part of a new approach for the description of attention (may be the most important part coming from a psychological point of view) is that it changes the responsibilities of our comprehension mechanisms for the selectivity of attention. As from Broadbent's inspiring works, this perceived opinion is that the selectivity of attention arises from the limitations of the brain capacity for processing information. At this point, attention selects the subdimension of the information that is obtained somehow and processed by a part of our perception system, until it passes to the next part of the system. Briefly, it is attention that selects the information to overcome bottlenecks of the limited capacity [14].

It is emphasized that the practice of paying attention is a requirement for coding, verifying and then recalling the information by the brain [21].

With regard to the sensual dimension of attention, it has been stated that the sense organs may cooperate to create a new pattern, but cannot sense two different patterns at the same time. However, it has been added that for the same pattern, several sense organs can cooperate [15].

Also, the efficiency of attention in the learning process has been defined strategically, for fulfilling the cognitive management strategies during the language learning [23].

Attention is defined as a meaningful activity that can be internalized, interested in and a mental activity that can cause to sustain the productivity and willingness. Also, it has been emphasized that attention can be controlled deliberately, however same does not apply for its intensity [24].

Attention is perceived as an activity of the organism and it is thought that it benefits from the nerve energy generated by the attention organ; it is also defined as an activity that enables the use of the energy required by the mechanism to perform the requested function [25]. In this context, attention should also be accepted as the foundation of the perceiving/sensing system.

When the concept is examined in this context, it has been seen that there is a development in terms of the definition of attention. Previously, attention being only on the individual basis and relevant for the interested objects and patterns, currently it is emphasized that the selectivity of attention should be focused on both individual and environment. 


\subsection{Attention in sports}

An important characteristic of those showing learned performance is their attention efficiency. The succesful performers do not only preserve their attention for long time, but they also note the descriptive and remarkable clues required for success [26].

A study has been conducted among cricketers in order to see if there is a correlation between their attention levels and performance levels, by describing the relation between their way to pay attention and sportive performances [27].

Upon examination of the results obtained from the on-going measurements of the attention studies carried out with four university student who were soccer players, it has been seen that these four players who had been subjected to attention training, have significantly improved their accuracy in terms of manifesting their soccer skills [28].

A study regarding the effect of the exercise stimulation on processing the visual information by children and adults has been conducted. The study has revealed that the selected children who are over 8 years old and adults show lower performance, and also their rank and characteristics are influenced by the age [29].

It has been reported that attention is particularly important in sports for figuring out the sportive process and that it has an important role in the development of performance as well as at the dissociation point where the mind deviates to other subjects outside the interest of the individual $[30,31]$. Also, there exist the studies targeting to emphasize the importance of attention at the point of conversion of the sportive performance into the score as well as a literature that shows that the shot performance and attention of the basketball players are significantly correlated $(\mathrm{r}=0.67)$ [32].

In a study conducted to evaluate the efficiency of attention in sports according to this very approach, the researchers have tried to analyse the expectations of the players in Greek national basketball, volleyball and water-polo teams with the help of the field expert trainers; and it has been reported that the basketball players are significantly different from others in terms of estimation and selective attention; the volleyball players are significantly different from others in terms of perceptual speed, focused attention, estimation as well as speed estimation and movement direction estimation and the water-polo players are significantly different in terms of perceiving the inexperienced players, visual reaction time and plane-based orientation $(\mathrm{p}<0.5)$ [33].

The literature supports the fact that different methods are used to evaluate attention in sports. However, it has been reported that none of these methods were completely sufficient in the process [34].

It has been indicated that the socio-economical status of the athletes is efficient to enable early physical relaxing and that the athletes at higher socio-economical level recover oxygen faster than other athletes. Whereas, it has been reported that the attention level is not related with the socio-economical level [35].

When attention is under threat, performance supervisor and motivational systems warn in combination, unproficiently and audibly. This effort process that requires attention continues until the individual regulates and control him/herself [24].

There is literature showing that attention can also be increased by using drugs [36]. Even the existence of this study shows the importance of attention in terms of performance.

The literature shows that attention is directly effective on several subdimensions of performance; formation of movement accuracy; controlling; describing the energy level required for the skill as well as the parameters that directly influence the performance.

The literature shows that the formula described to enable the required level of skill is very simple.

Skill $=$ Speed $x$ Accuracy $x$ Form $x$ Adaptability [37]. When the formula is examined, it is seen that the adaptability skill that describe the mental and psychological preparation, also defines attention as the most important element enabling the manisfestation of 
performance; and even this reason alone shows that attention is necessary not only for the manisfestation of the skill, but also for its manifestation at the required level.

\section{Material and method}

The study has been conducted according to the screening model. The screening model is a reasearch approach that targets to describe a past or present situtation as it is. The approach tries to describe any event, individual or object which is subject to the research as it is, under its own conditions. No effort is made to change or to affect them in any way. There is something to find out and it is out there. What is important is to "observe" properly and specify it [38].

\subsection{Study group}

A total of 174 persons studying at Dumlupınar University (DPU), Department of Physical Education and Sport (DPES) from different branches have been participated into the study group. The distribution of the participating students/athletes is as follows.

Table 1. Descriptive statistics of the participants

\begin{tabular}{|c|c|c|c|c|c|c|c|c|c|}
\hline & \multicolumn{6}{|c|}{ Branch } & \multirow[t]{2}{*}{ Total } \\
\hline & & & Soccer & Basketball & Volleyball & Handball & Athletics & Wrestling & \\
\hline \multirow{4}{*}{$\begin{array}{l}\frac{\bar{\theta}}{0} \\
\overline{0}\end{array}$} & \multirow{2}{*}{$\mathrm{F}$} & Count & 18 & 16 & 16 & 19 & 12 & 0 & 81 \\
\hline & & $\%$ of Total & $10,3 \%$ & $9,2 \%$ & $9,2 \%$ & $10,9 \%$ & $6,9 \%$ & $0,0 \%$ & $46,6 \%$ \\
\hline & \multirow{2}{*}{$\mathrm{M}$} & Count & 19 & 13 & 15 & 18 & 12 & 16 & 93 \\
\hline & & $\%$ of Total & $10,9 \%$ & $7,5 \%$ & $8,6 \%$ & $10,3 \%$ & $6,9 \%$ & $9,2 \%$ & $53,4 \%$ \\
\hline \multirow{2}{*}{\multicolumn{2}{|c|}{ Total }} & Count & 37 & 29 & 31 & 37 & 24 & 16 & 174 \\
\hline & & $\%$ of Total & $21,3 \%$ & $16,7 \%$ & $17,8 \%$ & $21,3 \%$ & $13,8 \%$ & $9,2 \%$ & $100,0 \%$ \\
\hline
\end{tabular}

Table 1 shows the $46,6 \%$ of the participating students are female and $53,4 \%$ of them are male. Also, according to the female participants' proportion to all athletes, $10,3 \%$ are soccer players; $9,2 \%$ are basketball players; $9,2 \%$ are volleyball players; $10,9 \%$ are handball players and $6,9 \%$ do athletics. According to the male participants' proportion to all athletes $10,9 \%$ are soccer players, $7,5 \%$ basketball players, $8,6 \%$ volleyball players, $10,3 \%$ hanball players, $6,9 \%$ do athletics and $9,2 \%$ are wrestlers.

A total of 174 persons with various ages, studying at Dumlupinar University, Department of Physical Education and Sport performing in different sport branches have been participated into the study group. The sport lives of the participants were still active at the time and $46,6 \%$ of them were female and $53,4 \%$ of them were male.

The system used in the research is a neurofeedback system that does not comprise any subcutaneous tool. The device registered in the name of Freer Logic, LLC measures the individual attention level using various sub-tests, on the basis of the individual's reactions to the content provided in the computer environment. The reactions are measured through instant data transfer between computer and the student.

The system is recalibrated for each individual. Accordingly, when the system is open using it for another individual requires recalibration by the authorized persons. The subtests used in the system are Attention Consistency, Staying Focused Against Time, Visual 
Follow-Up, Short Term Memory, Staying Focused Despite the Stimulators and Distractors, Controlling Attention, Hand-Eye-Brain Coordination, and Concentration.

\subsection{Evaluation of data and statistics}

The data obtained from the measurements carried out within the scope of the research have been evaluated using SPSS 22 software. The attention obtained by the participants have been evaluated considering also the characteristics of data, on the basis of the independent variables. In this context, for the groups having two different independent variables t-test with independent sample and for the groups having 3 or more independent variables ONEWAY ANOVA test have been used. Furthermore, in order to determine the differences between the groups, Bonferroni and Tamhane tests have been used. The significance level has been set as $\alpha=0,05$.

\section{Results (Findings)}

The data obtained in the research have been evaluated on the basis of the sub dimensions included in the Active Participation (AE) neurofeedback measurements and analysed in terms of the independent variables. Thus, the results have been indicated under five sub titles.

\subsection{Attention levels of the athletes according to gender variable}

The attention levels of the participating athletes according to the gender variable is as follows.

Table 2. The independent sample t-test results regarding the attention consistency of the participating athletes by gender

\begin{tabular}{|l|l|c|c|c|c|c|}
\hline & Gender & $\mathrm{N}$ & Mean & Std. Deviation & $\mathrm{T}$ & $\mathrm{P}$ \\
\hline \multirow{2}{*}{$\begin{array}{l}\text { Attention } \\
\text { Consistency }\end{array}$} & Female & 81 & 82,40 & 7,713 & & \multirow{3}{\mathbf{3},424}{} \\
\cline { 2 - 5 } & Male & 93 & 78,22 & 8,299 & $\mathbf{0 0 1}$ \\
\hline
\end{tabular}

Table 2 shows that the attention consistency skills of the participating female athletes $(\mathrm{N}=81)$ was $=82,4+7,713$ and for the male participants $(\mathrm{N}=93)$, this value was $=78,22+$ 8,299 . Table 2 also shows that on the basis of the gender variable, there is a significant difference favouring the female athletes $(\mathrm{t} .05=3,424 ; \mathrm{p}<0.05)$ with regard to the attention consistency.

Table 3. The independent sample t-test results regarding the visual follow-up sub tests of the participating athletes by gender

\begin{tabular}{|c|c|c|c|c|c|c|}
\hline & Gender & $\mathrm{N}$ & Mean & Std. Deviation & $\mathrm{T}$ & $\mathrm{P}$ \\
\hline \multirow{3}{*}{ Visual Follow-Up } & Female & 81 & 82,78 & 6,387 & & \\
\cline { 2 - 5 } & Male & 93 & 80,97 & 7,670 & \multirow{2}{*}{1,698} & \multirow{2}{*}{091} \\
\hline
\end{tabular}

Table 3 shows that no significant difference has been identified between the groups in the visual follow-up sub test by gender ( $\mathrm{t} .05=1,698 ; \mathrm{p}>0.05)$. 
Table 4. The independent sample t-test results regarding the staying focused sub tests of the participating athletes by gender

\begin{tabular}{|l|l|c|c|c|c|c|}
\hline & Gender & $\mathrm{N}$ & Mean & Std. Deviation & $\mathrm{T}$ & $\mathrm{P}$ \\
\hline \multirow{2}{*}{$\begin{array}{l}\text { Staying Focused } \\
\text { Against Time }\end{array}$} & Female & 81 & 83,46 & 5,727 & & \multirow{2}{*}{$\mathbf{3 , 9 7 4}$} \\
\cline { 2 - 6 } & Male & 93 & 79,08 & 8,684 & $\mathbf{0 , 0 0 0}$ \\
\hline
\end{tabular}

Table 4 shows that the staying focused against time skills of the participating female athletes $(\mathrm{N}=81)$ was $=83,46+5,727$ and for the male participants $(\mathrm{N}=93)$ this value was $=79,08+8,684$. Table 4 also shows that on the basis of the gender variable, there is a significant difference favouring the female athletes in terms of staying focused against time $(\mathrm{t} .05=3,974 ; \mathrm{p}<0.05)$.

Table 5. The independent sample t-test results regarding the short term memory sub tests of the participating athletes by gender

\begin{tabular}{|l|l|c|c|c|c|c|}
\hline & Gender & $\mathrm{N}$ & Mean & $\begin{array}{c}\text { Std. } \\
\text { Deviation }\end{array}$ & $\mathrm{T}$ & $\mathrm{P}$ \\
\hline \multirow{2}{*}{$\begin{array}{l}\text { Short Term } \\
\text { Memory }\end{array}$} & Female & 81 & 82,23 & 7,263 & \multirow{2}{*}{1,952} & 0,53 \\
\cline { 2 - 5 } & Male & 93 & 79,71 & 9,465 & \\
\hline
\end{tabular}

Table 5 shows that no significant difference has been identified between the groups in the short term memory sub test by gender (t.05=1,952; $>0.05)$.

Table 6. The independent sample t-test results regarding the staying focused despite stimulators and distractors sub tests of the participating athletes by gender

\begin{tabular}{|l|l|c|c|c|c|c|}
\hline & Gender & $\mathrm{N}$ & Mean & $\begin{array}{c}\text { Std. } \\
\text { Deviation }\end{array}$ & $\mathrm{T}$ & $\mathrm{P}$ \\
\cline { 1 - 5 } $\begin{array}{l}\text { Staying Focused } \\
\begin{array}{l}\text { Despite Stimulators } \\
\text { and Distractors }\end{array}\end{array}$ & Female & 81 & 81,84 & 8,433 & \multirow{2}{*}{0,936} & 0,351 \\
\cline { 2 - 5 } & 93 & 80,60 & 8,930 & \\
\hline
\end{tabular}

Table 6 shows that no significant difference has been identified between the groups in the staying focused despite stimulators and distractors sub test by gender ( $\mathrm{t} .05=0,936 ; \mathrm{p}>0.05$ ).

Table 7. The independent sample t-test results regarding the attention control sub tests of the participating athletes by gender

\begin{tabular}{|l|l|c|c|c|c|c|}
\hline & Gender & $\mathrm{N}$ & Mean & Std. Deviation & $\mathrm{T}$ & $\mathrm{P}$ \\
\hline \multirow{2}{*}{$\begin{array}{l}\text { Controlling } \\
\text { Attention }\end{array}$} & Female & 81 & 84,26 & 8,128 & \multirow{2}{*}{2,474} & \multirow{2}{*}{0,014} \\
\cline { 2 - 5 } & Male & 93 & 80,60 & 10,925 & & \\
\hline
\end{tabular}

Table 7 shows that the attention control skills of the participating female athletes $(\mathrm{N}=81)$ was $=84,26+8,128$ and for the male participants $(\mathrm{N}=93)$ this value was $=80,60$ $+10,925$. Table 7 also shows that on the basis of the gender variable, there is a significant 
difference favouring the female athletes in terms of attention control skills (t. $05=2,474$; $\mathrm{p}<0.05)$.

Table 8. The independent sample t-test results regarding the hand-eye-brain coordination sub tests of the participating athletes by gender

\begin{tabular}{|l|l|c|c|c|c|c|}
\hline & Gender & $\mathrm{N}$ & Mean & $\begin{array}{c}\text { Std. } \\
\text { Deviation }\end{array}$ & $\mathrm{T}$ & $\mathrm{p}$ \\
\hline $\begin{array}{l}\text { Hand-Eye-Brain } \\
\text { Coordination }\end{array}$ & Female & 81 & 84,40 & 5,781 & \multirow{2}{*}{3,498} & 0,001 \\
\cline { 2 - 5 } & Male & 93 & 80,92 & 7,113 & 3,13 \\
\hline
\end{tabular}

Table 8 shows that the hand-eye-brain of the participating female athletes $(\mathrm{N}=81)$ was $=84,40+5,781$ and for the male participants $(\mathrm{N}=93)$, this value was $=80,92+7,113$. Table 8 also shows that on the basis of the gender variable, there is a significant difference favouring the female athletes in terms of hand-eye-brain coordination (t.05=3,498; $\mathrm{p}<0.05$ ).

Table 9. The independent sample t-test results regarding the spatial memory sub tests of the participating athletes by gender

\begin{tabular}{|l|l|c|c|c|c|c|}
\hline & Gender & N & Mean & $\begin{array}{c}\text { Std. } \\
\text { Deviation }\end{array}$ & T & P \\
\hline \multirow{2}{*}{ Spatial Memory } & Female & 81 & 80,49 & 7,849 & \multirow{2}{*}{0,359} & 0,720 \\
\cline { 2 - 5 } & Male & 93 & 80,01 & 9,898 & \\
\hline
\end{tabular}

Table 9 shows that no significant difference has been identified between the groups in the spatial memory sub test by gender (t.05=0,359; $\mathrm{p}>0.05)$.

Table 10. The Independent Sample T-Test Results Regarding the Concentration Sub tests of the Participating Athletes by Gender

\begin{tabular}{|l|l|c|c|c|c|c|}
\hline & Gender & $\mathrm{N}$ & Mean & $\begin{array}{c}\text { Std. } \\
\text { Deviation }\end{array}$ & $\mathrm{T}$ & $\mathrm{p}$ \\
\hline \multirow{2}{*}{ Concentration } & Female & 81 & 83,31 & 7,361 & \multirow{2}{*}{3,942} & \multirow{2}{*}{, 000} \\
\cline { 2 - 5 } & Male & 93 & 78,23 & 9,614 & 3,942 \\
\hline
\end{tabular}

Table 10 shows that the concentration skills of the participating female athletes $(\mathrm{N}=81)$ was $=83,31+7,361$ and for the male participants $(\mathrm{N}=93)$ this value was $=78,23+9,614$. Table 10 also shows that on the basis of the gender variable, there is a significant difference favouring the female athletes in terms of concentration (t.05=3,942; $<<0.05)$.

\subsection{Attention levels of the athletes according to sports years}

The attention levels of the participating athletes according to the sports years variable is as follows. 
Table 11. The sub test regarding the attention consistency skills of the participating athletes by sports years

\begin{tabular}{|c|c|c|c|c|c|c|}
\hline & $\begin{array}{l}\text { Sports } \\
\text { Years }\end{array}$ & $\mathrm{N}$ & Mean & Std. Deviation & $\mathrm{F}$ & $\mathrm{p}$ \\
\hline \multirow{10}{*}{ 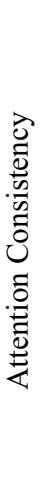 } & 5 & 12 & 79,83 & 7,030 & \multirow{10}{*}{0,637} & \multirow{10}{*}{0,746} \\
\hline & 6 & 12 & 79,08 & 9,737 & & \\
\hline & 7 & 12 & 78,17 & 8,167 & & \\
\hline & 8 & 28 & 81,14 & 7,012 & & \\
\hline & 10 & 26 & 81,23 & 7,163 & & \\
\hline & 11 & 33 & 80,73 & 9,362 & & \\
\hline & 12 & 15 & 82,60 & 7,059 & & \\
\hline & 13 & 17 & 78,18 & 10,327 & & \\
\hline & 15 & 19 & 78,26 & 8,685 & & \\
\hline & \begin{tabular}{|l|} 
Total \\
\end{tabular} & 174 & 80,16 & 8,277 & & \\
\hline
\end{tabular}

Upon comparison between the sports years groups, no significant difference has been found in terms of the attention consistency scores of the participating athletes $(\mathrm{F} 8,165=0,637 ; \mathrm{p}>0,05)$.

Table 12. The sub test regarding the visual follow-up skills of the participating athletes by sports years

\begin{tabular}{|c|c|c|c|c|c|c|}
\hline \multicolumn{2}{|c|}{ Sports Years } & $\mathrm{N}$ & Mean & Std. Deviation & $\mathrm{F}$ & $\mathrm{p}$ \\
\hline \multirow{10}{*}{ 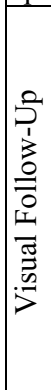 } & 5 & 12 & 83,25 & 6,690 & \multirow{10}{*}{0,492} & \multirow{10}{*}{0,861} \\
\hline & 6 & 12 & 79,42 & 10,247 & & \\
\hline & 7 & 12 & 82,17 & 5,766 & & \\
\hline & 8 & 28 & 82,57 & 5,872 & & \\
\hline & 10 & 26 & 82,31 & 7,336 & & \\
\hline & 11 & 33 & 81,00 & 7,215 & & \\
\hline & 12 & 15 & 83,53 & 5,817 & & \\
\hline & 13 & 17 & 81,35 & 8,717 & & \\
\hline & 15 & 19 & 80,84 & 7,335 & & \\
\hline & Total & 174 & 81,81 & 7,140 & & \\
\hline
\end{tabular}

Upon comparison between the sports years groups, no significant difference has been found in terms of the visual follow-up scores of the participating athletes $(\mathrm{F} 8,165=0,492$; $\mathrm{p}>0,05$ ). 
Table 13. The sub test regarding staying focused against time skills of the participating athletes by sports years

\begin{tabular}{|c|c|c|c|c|c|c|}
\hline \multicolumn{2}{|c|}{ Sports Years } & $\mathrm{N}$ & Mean & Std. Deviation & $\mathrm{F}$ & $\mathrm{p}$ \\
\hline \multirow{10}{*}{ 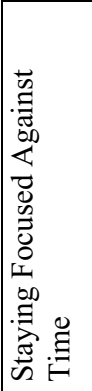 } & 5 & 12 & 83,25 & 6,635 & \multirow{10}{*}{0,539} & \multirow{10}{*}{0,826} \\
\hline & 6 & 12 & 80,58 & 8,795 & & \\
\hline & 7 & 12 & 82,67 & 5,176 & & \\
\hline & 8 & 28 & 80,93 & 6,503 & & \\
\hline & 10 & 26 & 80,62 & 10,016 & & \\
\hline & 11 & 33 & 81,39 & 6,910 & & \\
\hline & 12 & 15 & 82,00 & 4,408 & & \\
\hline & 13 & 17 & 81,76 & 7,250 & & \\
\hline & 15 & 19 & 78,32 & 11,076 & & \\
\hline & Total & 174 & 81,11 & 7,751 & & \\
\hline
\end{tabular}

Upon comparison between the sports years groups, no significant difference has been found in terms of the staying focused against time scores of the participating athletes $(\mathrm{F} 8,165=0,539 ; \mathrm{p}>0,05)$.

Table 14. The sub test regarding short term memory of the participating athletes by sports years

\begin{tabular}{|c|c|c|c|c|c|c|}
\hline \multicolumn{2}{|c|}{ Sports Years } & $\mathrm{N}$ & Mean & Std. Deviation & $\mathrm{F}$ & $\mathrm{p}$ \\
\hline \multirow{10}{*}{ 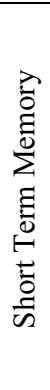 } & 5 & 12 & 80,00 & 7,769 & \multirow{10}{*}{,263 } & \multirow{10}{*}{,977 } \\
\hline & 6 & 12 & 80,42 & 8,939 & & \\
\hline & 7 & 12 & 79,58 & 5,089 & & \\
\hline & 8 & 28 & 81,21 & 7,608 & & \\
\hline & 10 & 26 & 79,62 & 11,997 & & \\
\hline & 11 & 33 & 81,55 & 8,537 & & \\
\hline & 12 & 15 & 82,87 & 6,390 & & \\
\hline & 13 & 17 & 81,53 & 8,804 & & \\
\hline & 15 & 19 & 80,53 & 8,959 & & \\
\hline & Total & 174 & 80,89 & 8,581 & & \\
\hline
\end{tabular}

Upon comparison between the sports years groups, no significant difference has been found in terms of the short term memory scores of the participating athletes $(\mathrm{F} 8,165=0,263$; $\mathrm{p}>0,05)$.

Table 15. The sub test regarding staying focused despite stimulators and distractors skills of the participating athletes by sports years

\begin{tabular}{|c|c|c|c|c|c|c|}
\hline \multicolumn{2}{|c|}{ Sports Years } & $\mathrm{N}$ & Mean & Std. Deviation & $\mathrm{F}$ & $\mathrm{p}$ \\
\hline \multirow{10}{*}{ 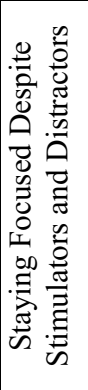 } & 5 & 12 & 82,33 & 5,774 & \multirow{10}{*}{0,492} & \multirow{10}{*}{0,861} \\
\hline & 6 & 12 & 81,42 & 7,982 & & \\
\hline & 7 & 12 & 83,75 & 7,533 & & \\
\hline & 8 & 28 & 80,82 & 9,113 & & \\
\hline & 10 & 26 & 81,69 & 7,176 & & \\
\hline & 11 & 33 & 78,97 & 9,548 & & \\
\hline & 12 & 15 & 82,73 & 5,824 & & \\
\hline & 13 & 17 & 80,94 & 12,153 & & \\
\hline & 15 & 19 & 81,32 & 10,028 & & \\
\hline & Total & 174 & 81,18 & 8,699 & & \\
\hline
\end{tabular}


Upon comparison between the sports years groups, no significant difference has been found in terms of the staying focused against stimulators and distractors scores of the participating athletes $(\mathrm{F} 8,165=0,492 ; \mathrm{p}>0,05)$.

Table 16. The sub test regarding attention control skills of the participating athletes by sports years

\begin{tabular}{|c|c|c|c|c|c|c|}
\hline \multicolumn{2}{|c|}{ Sports Years } & $\mathrm{N}$ & Mean & Std. Deviation & $\mathrm{F}$ & $\mathrm{p}$ \\
\hline \multirow{10}{*}{ 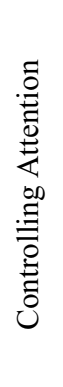 } & 5 & 12 & 84,00 & 8,146 & \multirow{10}{*}{0,798} & \multirow{10}{*}{0,605} \\
\hline & 6 & 12 & 83,92 & 5,282 & & \\
\hline & 7 & 12 & 84,58 & 5,384 & & \\
\hline & 8 & 28 & 82,86 & 6,473 & & \\
\hline & 10 & 26 & 80,77 & 11,459 & & \\
\hline & 11 & 33 & 82,48 & 9,843 & & \\
\hline & 12 & 15 & 84,00 & 7,464 & & \\
\hline & 13 & 17 & 82,94 & 8,743 & & \\
\hline & 15 & 19 & 77,84 & 17,231 & & \\
\hline & Total & 174 & 82,30 & 9,868 & & \\
\hline
\end{tabular}

Upon comparison between the sports years groups, no significant difference has been found in terms of the attention control scores of the participating athletes $(\mathrm{F} 8,165=0,798$; $\mathrm{p}>0,05$ ).

Table 17. The sub test regarding hand-eye-brain coordination of the participating athletes by sports years

\begin{tabular}{|c|c|c|c|c|c|c|}
\hline \multicolumn{2}{|c|}{ Sports Years } & $\mathrm{N}$ & Mean & Std. Deviation & $\mathrm{F}$ & $\mathrm{p}$ \\
\hline \multirow{10}{*}{  } & 5 & 12 & 83,75 & 5,707 & \multirow{10}{*}{0,672} & \multirow{10}{*}{0,715} \\
\hline & 6 & 12 & 83,50 & 4,964 & & \\
\hline & 7 & 12 & 83,83 & 7,334 & & \\
\hline & 8 & 28 & 83,29 & 5,530 & & \\
\hline & 10 & 26 & 81,42 & 7,834 & & \\
\hline & 11 & 33 & 81,36 & 7,557 & & \\
\hline & 12 & 15 & 83,87 & 7,772 & & \\
\hline & 13 & 17 & 83,65 & 3,481 & & \\
\hline & 15 & 19 & 80,79 & 8,004 & & \\
\hline & Total & 174 & 82,54 & 6,736 & & \\
\hline
\end{tabular}

Upon comparison between the sports years groups, no significant difference has been found in terms of the hand-eye-brain coordination scores of the participating athletes $(\mathrm{F} 8,165=0,672 ; \mathrm{p}>0,05)$.

Table 18. The sub test regarding spatial memory of the participating athletes by sports years

\begin{tabular}{|c|c|c|c|c|c|c|}
\hline \multicolumn{2}{|c|}{ Sports Years } & $\mathrm{N}$ & Mean & Std. Deviation & $\mathrm{F}$ & $\mathrm{p}$ \\
\hline \multirow{10}{*}{  } & 5 & 12 & 76,42 & 9,549 & \multirow{10}{*}{0,585} & \multirow{10}{*}{0,789} \\
\hline & 6 & 12 & 81,08 & 6,403 & & \\
\hline & 7 & 12 & 77,75 & 7,412 & & \\
\hline & 8 & 28 & 80,46 & 10,269 & & \\
\hline & 10 & 26 & 80,50 & 10,481 & & \\
\hline & 11 & 33 & 79,82 & 8,579 & & \\
\hline & 12 & 15 & 80,80 & 8,970 & & \\
\hline & 13 & 17 & 82,65 & 8,631 & & \\
\hline & 15 & 19 & 81,11 & 8,306 & & \\
\hline & Total & 174 & 80,24 & 8,980 & & \\
\hline
\end{tabular}


Upon comparison between the sports years groups, no significant difference has been found in terms of the spatial memory scores of the participating athletes $(F 8,165=0,585$; $\mathrm{p}>0,05)$.

Table 19. The sub test regarding concentration skills of the participating athletes by sports years

\begin{tabular}{|c|c|c|c|c|c|c|}
\hline \multicolumn{2}{|c|}{ Sports Years } & $\mathrm{N}$ & Mean & Std. Deviation & $\bar{F}$ & $\mathrm{p}$ \\
\hline \multirow{10}{*}{  } & 5 & 12 & 81,42 & 7,868 & \multirow{10}{*}{0,653} & \multirow{10}{*}{0,732} \\
\hline & 6 & 12 & 82,08 & 6,501 & & \\
\hline & 7 & 12 & 81,50 & 9,765 & & \\
\hline & 8 & 28 & 79,89 & 7,455 & & \\
\hline & 10 & 26 & 80,54 & 10,693 & & \\
\hline & 11 & 33 & 81,64 & 8,930 & & \\
\hline & 12 & 15 & 82,13 & 4,422 & & \\
\hline & 13 & 17 & 80,59 & 9,042 & & \\
\hline & 15 & 19 & 76,63 & 12,566 & & \\
\hline & Total & 174 & 80,59 & 8,982 & & \\
\hline
\end{tabular}

Upon comparison between the sports years groups, no significant difference has been found in terms of the concentration skills scores of the participating athletes $(F 8,165=0,653$; $\mathrm{p}>0,05)$.

\subsection{Attention levels of the athletes according to branches}

The attention levels of the participating athletes according to the sports branch variable is as follows.

Table 20. The sub test regarding the attention consistency skills of the participating athletes by sports branch

\begin{tabular}{|c|c|c|c|c|c|c|}
\hline \multicolumn{2}{|l|}{ Branch } & $\mathrm{N}$ & Mean & Std. Deviation & $\mathrm{F}$ & $\mathrm{p}$ \\
\hline \multirow{7}{*}{ 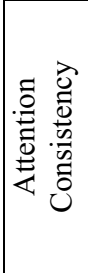 } & Soccer & 37 & 79,86 & 9,861 & \multirow{7}{*}{1,764} & \multirow{7}{*}{0,123} \\
\hline & Basketball & 29 & 79,41 & 7,204 & & \\
\hline & Volleyball & 31 & 80,10 & 7,049 & & \\
\hline & Handball & 37 & 82,68 & 6,770 & & \\
\hline & Athletics & 24 & 80,75 & 9,237 & & \\
\hline & Wrestling & 16 & 75,63 & 8,958 & & \\
\hline & Total & 174 & 80,16 & 8,277 & & \\
\hline
\end{tabular}

Upon comparison between the sports branch groups, no significant difference has been found in terms of the attention consistency scores of the participating athletes (F5,165=1,764; $\mathrm{p}>0,05)$.

Table 21. The sub test regarding the follow-up skills of the participating athletes by sports branch

\begin{tabular}{|c|c|c|c|c|c|c|}
\hline \multicolumn{2}{|c|}{ Branch } & $\mathrm{N}$ & Mean & Std. Deviation & $\mathrm{F}$ & $\mathrm{p}$ \\
\hline \multirow{7}{*}{ 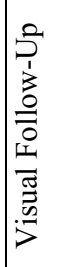 } & Soccer & 37 & 81,32 & 7,696 & \multirow{7}{*}{1,107} & \multirow{7}{*}{0,358} \\
\hline & Basketball & 29 & 82,79 & 5,759 & & \\
\hline & Volleyball & 31 & 80,87 & 8,310 & & \\
\hline & Handball & 37 & 83,70 & 5,661 & & \\
\hline & \begin{tabular}{|l} 
Athletics \\
\end{tabular} & 24 & 81,08 & 7,021 & & \\
\hline & Wrestling & 16 & 79,69 & 8,631 & & \\
\hline & Total & 174 & 81,81 & 7,140 & & \\
\hline
\end{tabular}


Upon comparison between the sports branch groups, no significant difference has been found in terms of the visual follow-up scores of the participating athletes (F5,165=1,107; $\mathrm{p}>0,05)$.

Table 22. The sub test regarding the staying focused against time skills of the participating athletes by sports branch

\begin{tabular}{|c|c|c|c|c|c|c|}
\hline \multicolumn{2}{|c|}{ Branch } & $\mathrm{N}$ & Mean & Std. Deviation & $\mathrm{F}$ & $\mathrm{p}$ \\
\hline \multirow{7}{*}{ 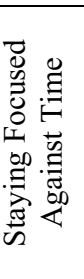 } & Soccer & 37 & 80,73 & 8,928 & \multirow{7}{*}{1,342} & \multirow{7}{*}{0,249} \\
\hline & Basketball & 29 & 82,55 & 6,015 & & \\
\hline & Volleyball & 31 & 79,39 & 11,053 & & \\
\hline & Handball & 37 & 82,81 & 4,364 & & \\
\hline & Athletics & 24 & 81,50 & 6,750 & & \\
\hline & Wrestling & 16 & 78,25 & 6,894 & & \\
\hline & Total & 174 & 81,11 & 7,751 & & \\
\hline
\end{tabular}

Upon comparison between the sports branch groups, no significant difference has been found in terms of the staying focused against time scores of the participating athletes $(\mathrm{F} 5,165=1,342 ; \mathrm{p}>0,05)$.

Table 23. The sub test regarding the short term memory of the participating athletes by sports branch

\begin{tabular}{|c|c|c|c|c|c|c|}
\hline & Branch & $\mathrm{N}$ & Mean & Std. Deviation & $\mathrm{F}$ & $\mathrm{p}$ \\
\hline \multirow{7}{*}{ 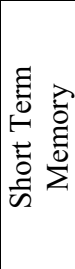 } & Soccer & 37 & 79,73 & 9,500 & \multirow{7}{*}{1,082} & \multirow{7}{*}{0,372} \\
\hline & Basketball & 29 & 82,59 & 6,395 & & \\
\hline & Volleyball & 31 & 80,06 & 12,514 & & \\
\hline & Handball & 37 & 82,89 & 5,087 & & \\
\hline & Athletics & 24 & 78,96 & 8,805 & & \\
\hline & Wrestling & 16 & 80,31 & 5,963 & & \\
\hline & Total & 174 & 80,89 & 8,581 & & \\
\hline
\end{tabular}

Upon comparison between the sports branch groups, no significant difference has been found in terms of the short term memory scores of the participating athletes (F5,165 $=1,082$; $\mathrm{p}>0,05)$.

Table 24. The sub test regarding the staying focused despite stimulators and distractors skills of the participating athletes by sports branch

\begin{tabular}{|c|c|c|c|c|c|c|}
\hline Branch & & $\mathrm{N}$ & Mean & Std. Deviation & $\mathrm{F}$ & $\mathrm{p}$ \\
\hline \multirow{7}{*}{  } & Soccer & 37 & 80,00 & 8,293 & \multirow{7}{*}{2,466} & \multirow{7}{*}{0,035} \\
\hline & Basketball & 29 & 83,66 & 7,654 & & \\
\hline & Volleyball & 31 & 80,26 & 9,381 & & \\
\hline & Handball & 37 & 84,16 & 5,781 & & \\
\hline & Athletics & 24 & 78,08 & 11,021 & & \\
\hline & Wrestling & 16 & 78,94 & 9,808 & & \\
\hline & Total & 174 & 81,18 & 8,699 & & \\
\hline
\end{tabular}

The comparison between the branch groups have revealed a significant difference in terms of the staying focused despite stimulators and distractors skills (F5,165 $=2,466$; $\mathrm{p}<0,05)$. In order to specify the groups showing the significant difference, Tamhane test has been applied as a second level test, since the variances were not homogen. However, no significant difference has been observed between the sub groups $(p>0,05)$. 
Table 25. The sub test regarding the attention control skills of the participating athletes by sports branch

\begin{tabular}{|c|c|c|c|c|c|c|}
\hline & nch & $\mathrm{N}$ & Mean & Std. Deviation & $\mathrm{F}$ & $\mathrm{P}$ \\
\hline \multirow{7}{*}{ 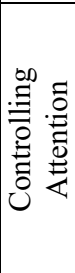 } & Soccer & 37 & 81,49 & 8,704 & \multirow{7}{*}{1,514} & \multirow{7}{*}{0,188} \\
\hline & Basketball & 29 & 84,41 & 6,489 & & \\
\hline & Volleyball & 31 & 78,81 & 15,041 & & \\
\hline & Handball & 37 & 83,89 & 8,027 & & \\
\hline & Athletics & 24 & 81,54 & 9,869 & & \\
\hline & Wrestling & 16 & 84,63 & 7,597 & & \\
\hline & Total & 174 & 82,30 & 9,868 & & \\
\hline
\end{tabular}

Upon comparison between the sports branch groups, no significant difference has been found in terms of the attention control scores of the participating athletes $(\mathrm{F} 5,165=1,514$; $\mathrm{p}>0,05)$.

Table 26. The sub test regarding the hand-eye-brain coordination of the participating athletes by sports branch

\begin{tabular}{|c|c|c|c|c|c|c|}
\hline \multicolumn{2}{|c|}{ Branch } & $\mathrm{N}$ & Mean & Std. Deviation & $\mathrm{F}$ & $\mathrm{P}$ \\
\hline \multirow{7}{*}{ 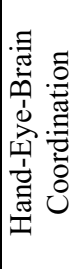 } & Soccer & 37 & 81,57 & 7,855 & \multirow{7}{*}{1,548} & \multirow{7}{*}{0,178} \\
\hline & Basketball & 29 & 83,45 & 5,262 & & \\
\hline & Volleyball & 31 & 82,35 & 9,506 & & \\
\hline & Handball & 37 & 83,73 & 4,011 & & \\
\hline & Athletics & 24 & 83,71 & 6,403 & & \\
\hline & Wrestling & 16 & 79,00 & 4,274 & & \\
\hline & Total & 174 & 82,54 & 6,736 & & \\
\hline
\end{tabular}

Upon comparison between the sports branch groups, no significant difference has been found in terms of the hand-eye-brain coordination scores of the participating athletes $(\mathrm{F} 5,165=1,548 ; \mathrm{p}>0,05)$.

Table 27. The sub test regarding the spatial memory of the participating athletes by sports branch

\begin{tabular}{|c|c|c|c|c|c|c|c|}
\hline \multicolumn{2}{|c|}{ Branch } & $\mathrm{N}$ & Mean & Std. Deviation & $\mathrm{F}$ & $\mathrm{P}$ & Groups \\
\hline \multirow{7}{*}{ 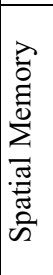 } & Soccer & 37 & 77,49 & 9,648 & \multirow{7}{*}{2,546} & \multirow{7}{*}{0,030} & \multirow{7}{*}{$\begin{array}{c}\text { Soccer- } \\
\text { Wrestling }\end{array}$} \\
\hline & Basketball & 29 & 81,69 & 8,528 & & & \\
\hline & Volleyball & 31 & 79,48 & 10,484 & & & \\
\hline & Handball & 37 & 81,86 & 6,588 & & & \\
\hline & Athletics & 24 & 77,88 & 9,373 & & & \\
\hline & Wrestling & 16 & 85,19 & 6,833 & & & \\
\hline & Total & 174 & 80,24 & 8,980 & & & \\
\hline
\end{tabular}

The comparison between the branch groups have revealed a significant difference in terms of the spatial memory skills $(\mathrm{F} 5,165=2,466 ; \mathrm{p}<0,05)$. In order to specify the groups showing the significant difference, Tamhane test has been applied as a second level test, since the variances were not homogen. The test results have revealed a significant difference in favour of wrestlers, between the soccer and wrestling groups $(p>0,05)$. 
Table 28. The sub test regarding the concentration skills of the participating athletes by sports branch

\begin{tabular}{|c|c|c|c|c|c|c|}
\hline \multicolumn{2}{|c|}{ Branch } & $\mathrm{N}$ & Mean & Std. Deviation & $\mathrm{F}$ & $\mathrm{P}$ \\
\hline \multirow{7}{*}{ 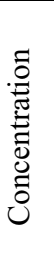 } & Soccer & 37 & 79,51 & 8,846 & \multirow{7}{*}{0,891} & \multirow{7}{*}{0,488} \\
\hline & Basketball & 29 & 82,66 & 6,773 & & \\
\hline & Volleyball & 31 & 80,26 & 13,117 & & \\
\hline & Handball & 37 & 80,89 & 6,288 & & \\
\hline & Athletics & 24 & 81,79 & 9,325 & & \\
\hline & Wrestling & 16 & 77,50 & 7,789 & & \\
\hline & Total & 174 & 80,59 & 8,982 & & \\
\hline
\end{tabular}

Upon comparison between the sports branch groups, no significant difference has been found in terms of the concentration scores of the participating athletes (F5, 165 $=0,891$; $\mathrm{p}>0,05)$.

\subsection{Attention levels of the athletes according to branch type variable}

The attention levels of the participating athletes according to the sports branch type variable is as follows.

Table 29. The sub test regarding the attention consistency skills of the participating athletes by branch type

\begin{tabular}{|l|l|c|c|c|c|c|}
\hline & B. Type & $\mathrm{N}$ & Mean & Std. Deviation & $\mathrm{T}$ & $\mathrm{P}$ \\
\hline \multirow{2}{*}{$\begin{array}{l}\text { Attention } \\
\text { Consistency }\end{array}$} & Individual & 41 & 78,76 & 9,251 & & \\
\cline { 2 - 5 } & Team & 133 & 80,59 & 7,940 & $-1,245$ & 0,215 \\
\hline
\end{tabular}

Table 29 shows that the attention consistency skills of the participating individual athletes $(\mathrm{N}=41)$ was $=78,76+9,251$ and for the team member athletes $(\mathrm{N}=133)$ this value was $=80,59+7,940$. Table 29 shows that there is no significant difference in terms of the attention consistency skills of the participating athletes, on the basis of the branch type variable (t.05=-1,245; $\mathrm{p}>0.05)$.

Table 30. The sub test regarding the visual follo-up skills of the participating athletes by branch type

\begin{tabular}{|l|l|c|c|c|c|c|}
\hline & B. Type & $\mathrm{N}$ & Mean & Std. Deviation & $\mathrm{T}$ & $\mathrm{P}$ \\
\hline Visual & Individual & 41 & 80,34 & 7,624 & & \\
\cline { 2 - 5 } Follow-Up & Team & 133 & 82,26 & 6,951 & $-1,512$ & 0,132 \\
\hline
\end{tabular}

Table 30 shows that the visual follow-up skills of the participating individual athletes $(\mathrm{N}=41)$ was $=80,34+7,624$ and for the team member athletes $(\mathrm{N}=133)$ this value was $=82,26+6,951$. Table 30 shows that there is no significant difference in terms of the visual follow-up skills of the participating athletes, on the basis of the branch type variable (t.05=$1,245 ; \mathrm{p}>0.05)$. 
Table 31. The sub test regarding the staying focused against time skills of the participating athletes by branch type

\begin{tabular}{|c|c|c|c|c|c|c|}
\hline & B. Type & $\mathrm{N}$ & Mean & $\begin{array}{c}\text { Std. } \\
\text { Deviation }\end{array}$ & $\mathrm{t}$ & $\mathrm{P}$ \\
\hline \multirow{2}{*}{$\begin{array}{l}\text { Staying Focused } \\
\text { Against Time }\end{array}$} & Individual & 41 & 80,22 & 6,825 & \multirow{2}{*}{,- 845} & \multirow{2}{*}{,399 } \\
\hline & Team & 133 & 81,39 & 8,019 & & \\
\hline
\end{tabular}

Table 31 shows that the staying focused against time skills of the participating individual athletes $(\mathrm{N}=41)$ was $=80,22+6,825$ and for the team member athletes $(\mathrm{N}=133)$ this value was $=81,39+8,019$. Table 31 shows that there is no significant difference in terms of the staying focused against time skills of the participating athletes, on the basis of the branch type variable (t.05=-0,845; $\mathrm{p}>0.05)$.

Table 32. The sub test regarding the short term memory of the participating athletes by branch type

\begin{tabular}{|l|l|c|c|c|c|c|}
\hline & B. Type & $\mathrm{N}$ & Mean & Std. Deviation & $\mathrm{t}$ & $\mathrm{P}$ \\
\hline \multirow{2}{*}{$\begin{array}{l}\text { Short Term } \\
\text { Memory }\end{array}$} & Individual & 41 & 79,71 & 7,753 & & \multirow{2}{*}{$-1,005$} \\
\cline { 2 - 5 } & Team & 133 & 81,25 & 8,816 & 0,316 \\
\hline
\end{tabular}

Table 32 shows that the short term memory of the participating individual athletes $(\mathrm{N}=41)$ was $=79,71+7,753$ and for the team member athletes $(\mathrm{N}=133)$ this value was $=81,25+8,816$. Table 32 shows that there is no significant difference in terms of short term memory skills of the participating athletes, on the basis of the branch type variable (t.05=$1,005 ; \mathrm{p}>0.05)$.

Table 33. The sub test regarding the staying focused despite stimulators and distractors skills of the participating athletes by branch type

\begin{tabular}{|c|l|c|c|c|c|c|}
\hline & B. Type & N & Mean & Std. Deviation & T & P \\
\hline $\begin{array}{c}\text { Staying Focused } \\
\text { Despite Stimulators } \\
\text { and Distractors }\end{array}$ & Individual & 41 & 78,41 & 10,300 & & \\
\cline { 2 - 5 } & Team & 133 & 82,03 & 7,995 & $-2,064$ &, 044 \\
\hline
\end{tabular}

Table 33 shows that the staying focused despite stimulators and distractors skills of the participating individual athletes $(\mathrm{N}=41)$ was $=78,41+10,300$ and for the team member athletes $(\mathrm{N}=133)$ this value was $=82,03+7,995$. Table 33 shows that there is a significant difference in terms of the staying focused despite stimulators and distractors skills of the participating athletes, on the basis of the branch type variable $(\mathrm{t} .05=-2,064 ; \mathrm{p}<0.05)$.

Table 34. The sub test regarding the attention control of the participating athletes by branch type

\begin{tabular}{|l|l|c|c|c|c|c|}
\hline & B. Type & $\mathrm{N}$ & Mean & Std. Deviation & $\mathrm{T}$ & $\mathrm{P}$ \\
\hline \multirow{4}{*}{ Controlling Attention } & Individual & 41 & 82,73 & 8,944 & & \\
\cline { 2 - 5 } & Team & 133 & 82,17 & 10,163 & \multirow{2}{*}{, 316} & \multirow{2}{*}{, 752} \\
\hline
\end{tabular}

Table 34 shows that the attention control skills of the participating individual athletes $(\mathrm{N}=41)$ was $=82,73+8,944$ and for the team member athletes $(\mathrm{N}=133)$ this value was 
$=82,17+10,163$. Table 34 shows no significant difference in terms of the attention control skills of the participating athletes, on the basis of the branch type variable (t. $05=0,316$; $\mathrm{p}>0.05$ ).

Table 35. The sub test regarding the hand-eye-brain coordination of the participating athletes by branch type

\begin{tabular}{|l|l|c|c|c|c|c|}
\hline & B. Type & $\mathrm{N}$ & Mean & Std. Deviation & $\mathrm{T}$ & $\mathrm{P}$ \\
\hline \multirow{2}{*}{$\begin{array}{l}\text { Hand-Eye-Brain } \\
\text { Coordination }\end{array}$} & Individual & 41 & 81,76 & 5,995 & \multirow{2}{*}{$-0,852$} & \multirow{2}{*}{, 395} \\
\cline { 2 - 5 } & Team & 133 & 82,78 & 6,951 & & \\
\hline
\end{tabular}

Table 35 shows that the hand-eye-brain coordination of the participating individual athletes $(\mathrm{N}=41)$ was $=81,76+5,995$ and for the team member athletes $(\mathrm{N}=133)$ this value was $=82,78+6,951$. Table 35 shows no significant difference in terms of the hand-eyebrain coordination of the participating athletes, on the basis of the branch type variable (t.05=-0,852; $\mathrm{p}>0.05$ ).

Table 36. The sub test regarding the spatial memory of the participating athletes by branch type

\begin{tabular}{|l|l|c|c|c|c|c|}
\hline & B. Type & N & Mean & Std. Deviation & t & P \\
\hline \multirow{2}{*}{$\begin{array}{l}\text { Spatial } \\
\text { Memory }\end{array}$} & Individual & 41 & 81,12 & 9,225 & \multirow{2}{*}{, 722} & \multirow{2}{*}{, 471} \\
\cline { 2 - 5 } & Team & 133 & 79,96 & 8,921 & & \\
\hline
\end{tabular}

Table 36 shows that the spatial memory of the participating individual athletes $(\mathrm{N}=41)$ was $=81,12+9,225$ and for the team member athletes $(\mathrm{N}=133)$ this value was $=79,96+$ 8,921 . Table 36 shows no significant difference in terms of the spatial memory of the participating athletes, on the basis of the branch type variable ( $\mathrm{t} .05=0,722 ; \mathrm{p}>0.05)$.

Table 37. The sub test regarding the concentration of the participating athletes by branch type

\begin{tabular}{|l|l|c|c|c|c|c|}
\hline & B. Type & $\mathrm{N}$ & Mean & $\begin{array}{c}\text { Std. } \\
\text { Deviation }\end{array}$ & $\mathrm{T}$ & $\mathrm{P}$ \\
\hline \multirow{3}{*}{ Concentration } & Individual & 41 & 79,88 & 8,875 & \multirow{2}{*}{,- 581} & \multirow{2}{*}{, 562} \\
\cline { 2 - 5 } & Team & 133 & 80,81 & 9,037 &,- 52 \\
\hline
\end{tabular}

Table 37 shows that the concentration of the participating individual athletes $(\mathrm{N}=41)$ dikkati yoğunlaştırabilme alt testinde $=79,88+8,875$ and for the team member athletes $(\mathrm{N}=133)$ this value was $=80,81+9,037$. Table 37 shows no significant difference in terms of the concentration of the participating athletes, on the basis of the branch type variable (t.05=-0,581; $>0.05)$.

\subsection{Attention levels of the athletes according to membership in national teams}

The attention levels of the participating athletes according to the membership to the national teams is as follows.

The attention consistency results of the participating athletes in terms of the national team membership are indicated in the below table (Table 38). 
Table 38. The sub test regarding the attention consistency skills of the participating athletes by branch type

\begin{tabular}{|l|l|c|c|c|c|c|}
\hline & National Team Membership & $\mathrm{N}$ & Mean & Std. Deviation & $\mathrm{t}$ & $\mathrm{P}$ \\
\hline \multirow{2}{*}{$\begin{array}{l}\text { Attention } \\
\text { Consistency }\end{array}$} & Yes & 38 & 84,11 & 6,517 & \multirow{2}{*}{3,568} & \multirow{2}{*}{, 001} \\
\cline { 2 - 7 } & No & 136 & 79,56 & 8,293 & & \\
\hline
\end{tabular}

Table 38 shows that the attention consistency of the national athletes $(\mathrm{N}=38)$ was $=$ $84,11+6,517$ and for those athletes who were not members of the national teams $(\mathrm{N}=136)$ this value was $=79,56+8,293$. Table 38 shows that there is a significant difference in terms of attention skills between the athletes who are member of the national teams and those who are not, on the basis of the national team membership variable (t. $05=3,568$; $\mathrm{p}<0.05)$.

Table 39. The sub test regarding the visual follow-up skills of the participating athletes by branch type

\begin{tabular}{|l|l|c|c|c|c|c|}
\hline & $\begin{array}{l}\text { National } \\
\text { Team } \\
\text { Membership }\end{array}$ & $\mathrm{N}$ & Mean & Std. Deviation & $\mathrm{t}$ & $\mathrm{P}$ \\
\hline Visual & Yes & 38 & 84,16 & 5,587 & \multirow{2}{*}{2,313} & \multirow{2}{*}{024} \\
\cline { 2 - 6 } Follow-Up & No & 136 & 81,63 & 7,171 & \\
\hline
\end{tabular}

Table 39 shows that the visual follow-up of the national athletes $(\mathrm{N}=38)$ was $\bar{X}=$ $84,16 \pm 5,587$ and for those athletes who were not members of the national teams $(\mathrm{N}=136)$ this value was $\bar{X}=81,63 \pm 7,171$. Table 39 shows that there is a significant difference in terms of visual follow-up skills between the athletes who are member of the national teams and those who are not, on the basis of the national team membership variable $\left(\mathrm{t}_{.05}=2,313\right.$; $\mathrm{p}<0.05)$.

Table 40. The sub test regarding the staying focused against time skills of the participating athletes by branch type

\begin{tabular}{|l|l|c|c|c|c|c|}
\hline & National Team Membership & N & Mean & Std. Deviation & T & $p$ \\
\hline $\begin{array}{l}\text { Staying Focused } \\
\text { Against Time }\end{array}$ & Yes & 38 & 82,45 & 6,272 & & \\
\cline { 2 - 5 } & No & 136 & 80,89 & 8,014 & 1,106 &, 270 \\
\hline
\end{tabular}

Table 40 shows that the staying focused against time skills of the national athletes $(\mathrm{N}=38)$ was $=82,45+6,272$ and for those athletes who were not members of the national teams $(\mathrm{N}=136)$ this value was $=80,89+8,014$. Table 40 shows that there is no significant difference in terms of staying focused against time skills between the athletes who are member of the national teams and those who are not, on the basis of the national team membership variable (t.05 $=1,106 ; \mathrm{p}>0.05)$. 
Table 41. The sub test regarding the short time memory skills of the participating athletes by branch type

\begin{tabular}{|l|l|c|c|c|c|c|}
\hline & $\begin{array}{l}\text { National Team } \\
\text { Membership }\end{array}$ & $\mathrm{N}$ & Mean & $\begin{array}{c}\text { Std. } \\
\text { Deviation }\end{array}$ & $\mathrm{T}$ & $\mathrm{p}$ \\
\cline { 1 - 5 } $\begin{array}{l}\text { Short Term } \\
\text { Memory }\end{array}$ & Yes & 38 & 82,11 & 6,370 & \multirow{2}{*}{, 805} & \multirow{2}{*}{, 422} \\
\cline { 2 - 5 } & No & 136 & 80,85 & 9,030 & \\
\hline
\end{tabular}

Table 41 shows that short term memory skills of the national athletes $(\mathrm{N}=38)$ was $=$ $82,11+6,370$ and for those athletes who were not members of the national teams $(\mathrm{N}=136)$ this value was $=80,85+9,030$. Table 41 shows that there is no significant difference in terms of short time memory skills between the athletes who are member of the national teams and those who are not, on the basis of the national team membership variable (t.05 $=0,805 ; \mathrm{p}>0.05)$.

Table 42. The sub test regarding the staying focused despite stimulators and distractors skills of the participating athletes by branch type

\begin{tabular}{|c|l|c|c|c|c|c|}
\hline & $\begin{array}{l}\text { National } \\
\text { Team } \\
\text { Membership }\end{array}$ & $\mathrm{N}$ & Mean & $\begin{array}{c}\text { Std. } \\
\text { Deviation }\end{array}$ & $\mathrm{T}$ & $\mathrm{p}$ \\
\hline $\begin{array}{c}\text { Staying Focused } \\
\text { Despite Stimulators } \\
\text { and Distractors }\end{array}$ & Nes & 38 & 84,53 & 5,129 & \multirow{2}{*}{2,563} &, 012 \\
\cline { 2 - 5 } & 136 & 81,70 & 8,449 & \\
\hline
\end{tabular}

Table 42 shows that the staying focused despite stimulators and distractors skills of the national athletes $(\mathrm{N}=38)$ was $=84,53+5,129$ and for those athletes who were not members of the national teams $(\mathrm{N}=136)$ this value is $=81,70+8,449$. Table 42 shows that there is a significant difference in terms of staying focused despite stimulators and distractors skills in favour of the national athletes, between the athletes who are member of the national teams and those who are not, on the basis of the national team membership variable (t.05=2,563; $<<0.05)$.

Table 43. The sub test regarding the attention control skills of the participating athletes by branch type

\begin{tabular}{|l|l|c|c|c|c|c|}
\hline & National Team Membership & $\mathrm{N}$ & Mean & Std. Deviation & $\mathrm{t}$ & $\mathrm{P}$ \\
\hline \multirow{3}{*}{ Controlling Attention } & Yes & 38 & 84,47 & 5,954 & \multirow{3}{*}{0} & \\
\cline { 2 - 6 } & No & 136 & 82,15 & 10,365 & & \multirow{2}{*}{079} \\
\hline
\end{tabular}

Table 43 shows that the attention control skills of the national athletes $(\mathrm{N}=38)$ was $=$ $84,47+5,954$ and for those athletes who were not members of the national teams $(\mathrm{N}=136)$ this value was $=82,15+10,365$. Table 43 shows that there is a significant difference in terms of attention contrl skills in favour of the national athletes, between the athletes who are member of the national teams and those who are not, on the basis of the national team membership variable $(\mathrm{t} .05=2,563 ; \mathrm{p}<0.05)$. 
Table 44. The sub test regarding the hand-eye-brain coordination of the participating athletes by branch type

\begin{tabular}{|l|l|c|c|c|c|c|}
\hline & National Team Membership & N & Mean & Std. Deviation & T & P \\
\hline \multirow{2}{*}{$\begin{array}{l}\text { Hand-Eye-Brain } \\
\text { Coordination }\end{array}$} & Yes & 38 & 84,00 & 5,261 & & \\
\cline { 2 - 5 } & No & 136 & 82,29 & 7,029 & 1,390 &, 166 \\
\hline
\end{tabular}

Table 44 shows that the hand-eye-brain coordination of the national athletes $(\mathrm{N}=38)$ was $=84,00+5,261$ and for those athletes who were not members of the national teams $(\mathrm{N}=136)$ this value was $=82,29+7,029$. Table 44 shows that there is no significant difference in terms of hand-eye-brain coordination between the athletes who are member of the national teams and those who are not, on the basis of the national team membership variable (t.05 $=1,390 ; \mathrm{p}>0.05)$.

Table 45. The sub test regarding the spatial memory skills of the participating athletes by branch

\begin{tabular}{|l|l|c|c|c|c|c|}
\hline & National Team Membership & N & Mean & Std. Deviation & T & P \\
\hline \multirow{2}{*}{$\begin{array}{l}\text { Spatial } \\
\text { Memory }\end{array}$} & Yes & 38 & 80,53 & 9,209 & & \\
\cline { 2 - 7 } & No & 136 & 80,30 & 8,916 & \multirow{2}{*}{, 136} &, 892 \\
\hline
\end{tabular}

Table 45 shows that the spatial memory skills of the national athletes $(\mathrm{N}=38)$ was $=$ $80,53+9,209$ and for those athletes who were not members of the national teams $(\mathrm{N}=136)$ this value was $=80,30+8,916$. Table 45 shows that there is no significant difference in terms of spatial memory skills between the athletes who are member of the national teams and those who are not, on the basis of the national team membership variable (t. $05=0,136$; $\mathrm{p}>0.05)$.

Table 46. The sub test regarding the concentration skills of the participating athletes by branch type

\begin{tabular}{|l|l|c|c|c|c|c|}
\hline & National Team Membership & N & Mean & Std. Deviation & T & P \\
\hline \multirow{3}{*}{ Concentration } & Yes & 38 & 81,47 & 8,526 & \multirow{3}{*}{, 493} & \multirow{2}{*}{, 623} \\
\cline { 2 - 7 } & No & 136 & 80,66 & 9,104 & & \\
\hline
\end{tabular}

Table 46 shows that the concentration skills of the national athletes $(\mathrm{N}=38)$ was $=$ $81,47+8,526$ and for those athletes who were not members of the national teams $(\mathrm{N}=136)$ this value was $=80,66+9,104$. Table 46 shows that there is no significant difference in terms of concentration skills between the athletes who are member of the national teams and those who are not, on the basis of the national team membership variable (t. $05=0,493$; $\mathrm{p}>0.05)$.

\section{Conclusion (Discussion)}

The results of the research have revealed that there is a significant difference in favour of female participants with regard to the attention consistency, staying focused against time, controlling attention, hand-eye-brain coordination and concentration skills when compared to the male participants (See Table 2,4,7,8,10). This result showing once again the above mentioned gender based characteristics of females, or in other words, males' lower 
performance in these skills implies that the infrastructure establishment efforts are not based on an efficient planning.

The analysis by the sports years variable has showed that the variations observed between the groups in terms of attention are not influenced by latter (See Table $11,12,13,14,15,16,17,18,19)$. Considering that the sports years variable influences the performance in several aspects except attention $(\mathrm{p}>0,05)$, it has been concluded that although certain level of experience is required for attention, the real determinant is the instant performance. Accordingly, there is no past in terms of performance in the sports, there is only today and if you win today, you are the champion. In the next competition, your competitors would see you only as the winner of the previous competition and you can still lose. Another result that can be analysed concordantly with this, seems to be the comparisons in terms of membership of the national team. The significant differences $(\mathrm{p}<0,05$; See Table 38,39,42) observed between the athletes who are members of the national teams and those who are not in terms of attention consistency, visual follow-up and staying focused despite the stimulators and distractors skills have revealed that attention is an efficient factor in every aspect for the participating athletes and they hold it as a characteritics. However, they underperform when it comes to use attention for the success. According to the research results, we can conclude that in order to be a national athlete, high level of attention consistency, visual follow-up and staying focused despite the stimulators and distractors skills are required. The existence of other studies that show the significant correlation between high level performance and concentration in the literature, supports the results of the present research [1]. Also indicated in the literature is that independently from the sports branch, the staying focused despite stimulators and distractors skill is efficient for showing the required performance [39]. Another finding of the present research, higher attention level in focusing on the target despite external factors, is also supported by the literature [40]. In addition, there are certain studies that show that internal focalization influence the performance negatively [41]. In the studies conducted among the 3rd grade students with the visual and audible attention stimulators for the on going motor skills, it has been observed that the skill level significantly increases for those who do it[42]. Furthermore, certain studies show that it is possible to increase the performance by keeping attention alerted through medication [36].

The research conducted by Olsen among top level athletes, normal level athletes and non-athletes has revealed that the top level athletes are significantly $(p<0,05)$ better in terms of reaction time, understanding and anxiety process compared to other groups. Also, it has been seen that the normal level athletes are significantly $(p<0,05)$ more successful in terms of the subdimensions, compared to those do not do any sports [43].

In a study carried out in 1988, it has been concluded that among the university students, the attention level of the female students were higher after the recreational running activities, compared to the male students and the attention level of the recreational runners was higher than those who do not run [44].

Furthermore, with regard to the spatial memory dimension, the researches have revealed that the training based on focusing on the factors in the close neighborhood affects the performance positively compared to the training based on internal focalization [45]. With regard to the spatial memory dimension, the research has revealed that the wrestlers' spatial memory skills are significantly different than soccer players. This implies that the competition area that is specific to branch is also influential.

The research results show that attention is an efficient factor for high performance; from the gender point of view, the attention skills of the female athletes are better than those of the males; the athletes should consider attention as a factor in the way to be accepted into national sports teams and establish their programs accordingly; and finally, the sports years is not an efficient variable in terms of attention. 
In this context, on the basis of the research results;

Attention should be included in the training programs as a situational variable. More detailed studies should be conducted in terms of the efficiency of the mental trainings. Attention should be systematically analysed and the working areas should be enriched according to the different environments and athletes.

\section{Acknowledgment}

This study has been generated under a project carried out by Dumlupinar University Scientific Researcj Projects Commission (Proje No: 2015-61).

\section{References}

1. Vast, Young, and Thomas, Emotions in sport: Perceived effects on attention, concentration, and performance. Aust Psychol, 45, 2,132-140 (2010)

2. Vuijk, et al., Motor performance of children with mild intellectual disability and borderline intellectual functioning. J Intell Disabil Res, 54, 955-965 (2010)

3. Yan, Cognitive styles affect choice response time and accuracy. Personality and Individual Differences, 48, 6, 747-751, (2010)

4. Gutierrez Diaz del Campo, et al., Differences in Decision-Making Development between Expert and Novice Invasion Game Players. Percept Motor Skill, 112, 3, 871888 (2011)

5. Hickey, Fricker, Attention deficit hyperactivity disorder, CNS stimulants and sport. Sports Med, 27, 1, 11-21 (1999)

6. Parr, Attention-Deficit Hyperactivity Disorder and the Athlete: New Advances and Understanding. Clinics in Sports Medicine, 30, 3, 591-+ (2011)

7. Conant-Norville and Tofler, Attention deficit/hyperactivity disorder and psychopharmacologic treatments in the athlete. Clinics in Sports Medicine, $24,4,829-+$ (2005)

8. Corrigan, Attention deficit hyperactivity disorder in sport: A review. Int J Sports Med, 24,7, 535-540 (2003)

9. Saemi, et al., Adopting an external focus of attention facilitates motor learning in children with attention deficit hyperactivity disorder. Kinesiology, 45, 2, 179-185 (2013)

10. Lee, Dunn,Holt, Youth Sport Experiences of Individuals With Attention Deficit/Hyperactivity Disorder. Adapt Phys Act Q, 31, 4, 343-361 (2014)

11. Putukian, et al., Attention Deficit Hyperactivity Disorder and the Athlete: An American Medical Society for Sports Medicine Position Statement (vol 21, pg 392, 2011). Clin J Sport Med, 22, 1, 79-79 (2012)

12. Putukian, et al., Attention Deficit Hyperactivity Disorder and the Athlete: An American Medical Society for Sports Medicine Position Statement. Clin J Sport Med, 21, 5, 392$401(2011)$

13. Solso, Maclin, and Maclin, Cognitive Psychology. İstanbul: Kitabevi (2013)

14. Wu, Smithies, and Mole, Attention : Philosophical and Psychological Essays. Oxford [England]: Oxford University Press. (2011)

15. Tsotsos, A Computational Perspective on Visual Attention. Cambridge, Mass: The MIT Press. (2011)

16. Nikolajeva, Reading for Learning : Cognitive Approaches to Children's Literature. Children's Literature, Culture, and Cognition. Amsterdam: John Benjamins Publishing Company. (2014) 
17. Carré and Hiemstra, A Feast of Learning : International Perspectives on Adult Learning and Change. Adult Education Special Topics: Theory, Research, and Practice in Lifelong Learning, Charlotte, N.C.: Information Age Publishing (2013)

18. Lim and Tay, Creating Holistic Technology-enhanced Learning Experiences : Tales From a Future School in Singapore. Rotterdam: Sense Publishers (2013)

19. Webster and Stewart, Problematizing Service-learning : Critical Reflections for Development and Action. Charlotte, N.C.: Information Age Publishing (2011)

20. Posner and Bodies, Components of Attention Psychol Rev, 78, 5, 391-408 (1971)

21. Steinmetz and Kensinger, Emotion's Effects on Attention and Memory : Relevance to Posttraumatic Stress Disorder. Psychology of Emotions, Motivations and Actions. Hauppauge, N.Y.: Nova Science Publishers, Inc. (2010)

22. French and Simpson, Attention, Cooperation, Purpose : An Approach to Groups Using Insights From the Work of Bion. London: Karnac Books (2014)

23. Thoma, Strategic Attention in Language Testing : Metacognition in a Yes/no Business English Vocabulary Test. European University Studies. Reihe XXI, Linguistik. Frankfurt am Main: Peter Lang AG. (2011)

24. Bruya, Effortless Attention : A New Perspective in the Cognitive Science of Attention and Action. Cambridge, Mass: A Bradford Book (2010)

25. Marchetti, Consciousness, Attention and Meaning. Psychology Research Progress. New York: Nova Science Publishers, Inc. (2010)

26. Schmidt and Wrisberg, Motor Learning and Performance A Situation - Based Learning Approach. Ankara: Anı Yayıncilik (2012)

27. Summers and Maddocks, Attentional Profiles of Cricket Players. Journal of Sport Psychology, 9, 3, 199-199 (1987)

28. Ziegler, The effects of attentional shift training on the execution of soccer skills: a preliminary investigation. Journal of Applied Behavior Analysis, 27, 545-552 (1994)

29. Deakin, Starkes, and Elliott, Feature integration of children during exercise. J Sport Exercise Psy, 10, 248-261 (1988)

30. Hill, Pay attention! JOPERD: The Journal of Physical Education, Recreation \& Dance, 62, 18-20 (1991).

31. Sargent, Developing a mental skills training program. Sports Coach, 20, 1 (1997)

32. Wilson and Kerr, Attentional style and basketball shooting. Perceptual \& Motor Skills, 73, 1025-1026 (1991)

33. Kioumourtzoglou, Kourtessis, and Michalopoulou, Differences in several perceptual abilities between experts and novices in basketball, volleyball and water-polo. Perceptual \& Motor Skills, 86, 3, 899-912 (1998)

34. Summers, Miller, Ford, Attentional style and basketball performance. J Sport Exercise Psy, 13, 239-253 (1991)

35. Smith, Gill, Crews, Attentional strategy use by experienced distance runners: physiological and psychological effects. Research Quarterly for Exercise \& Sport, 66, 142-150 (1995)

36. Biological Aids to Improve Performance. Journal of Sport Psychology, 7, 4, 330-330 (1985)

37. Johnson, Skill=SpeedXAccuracyXFormXAdaptability. Philadelphia: Lea \& Febiger (1972)

38. Karasar, Bilimsel Araştırma Yöntemi. 15. ed. Ankara: Nobel Yayın Dağıtım (2005)

39. Lawrence, et al., Internal and External Focus of Attention in a Novice Form Sport. Research Quarterly for Exercise \& Sport, 82, 3, 431-441 (2011)

40. Shafizadeh, McMorris, Sproule, Effect of different external attention of focus instruction on learning of golf putting skilL. Perceptual \& Motor Skills, 113, 2, 622-670 (2011) 
41. Weiss, The Effects of Reinvestment of Conscious Processing on Switching Focus of Attention. Research Quarterly for Exercise \& Sport, 82, 1, 28-36 (2011)

42. Mortimer, et al., Sport stacking in auditory and visual attention of grade 3 learners. Perceptual \& Motor Skills, 112, 4, 98-112 (2011)

43. Olsen, Relationship between psychological capacities and success in college athletics. Research Quarterly of the American Association for Health, Physical Education \& Recreation, 27, 79-89 (1956)

44. Wrisberg, Pein, Past running experience as a mediator of the attentional focus of male and female recreational runners. Perceptual \& Motor Skills, 70, 427-432 (1990)

45. Merchant, et al., Instructions to Adopt an External Focus Enhance Muscular Endurance. Research Quarterly for Exercise \& Sport, 82, 3, 466-473 (2011) 